\title{
Characterization of Infectious and Defective Cloned Avian Hepadnavirus Genomes
}

\author{
GERHILD WILDNER, DORIS FERNHOLZ, ROLF SPRENGEL, 'RALF SCHNEIDER, AND HANS WILL \\ Max-Planck-Institut für Biochemie, Martinsried/München, Germany
}

Received March 27, 1991; accepted August 1, 1991

\begin{abstract}
The infectivity in vivo, replication competence in vitro, and expression of viral genes of several molecularly cioned duck hepatitis B virus (DHBV) genomes were investigated. In addition, replication competence, core protein expression, and secretion of viral proteins were investigated for a grey heron hepatitis B virus genome. Except two, all DHBV isolates tested induced a systemic infection in Pekin ducks when injected as cloned viral DNA into the tiver. After transfection of chicken hepatoma cells, both defective DHBV genomes expressed intracellular nucleocepald and pre-S envelope proteins and secreted DHBs/pre-S particles into the medium. One of the defective DHBV genomes and HHBV produced within the cells replicative intermediates encapsidated in core particles and secreted virions, whereas the other defective DHBV genome did not and was unable to efficiently encapsidate the RNA pregenome, Cemparative sequence analysis was performed to identify potential amino acid changes in viral proteins of both defective DHBV genomes. The data obtained demonstrate that most cloned avian hepadnaviruses are infectious or replication competent and suggest defects in envelope, polymerase or encapsidation function, respectively, in two cloned DHBV genomes. (c) 1991 Academic Press, Inc.
\end{abstract}

\section{INTRODUCTION}

Members of the family of hepatitis B viruses (hepadnaviruses) have been isolated, cloned, and sequenced from human (HBV), woodchucks (WHV), ground squirrels (GSHV), Pekin ducks and a goose (DHBV). and from herons (HHBV) (for review see Marion, 1988; and Schodel et al., 1989, 1991). All hepadnaviruses induce acute and chronic infections. Mammalian hepadnaviruses are to various degrees pathogenic whereas those of birds are not (Marion, 1988). Replication of all hepadnaviruses involves synthesis of an RNA pregenome which is reverse transcribed into minus strand DNA which in turn is transcribed into a DNA plus strand by a DNA polymerase (Will et al., 1987). Both the reverse transcriptase (RTase) and the DNA polymerase and in addition an RNase $\mathrm{H}$ activity are virus encoded (for review see Schodel et al., 1989, 1991). Similar to retroviruses the RTase probably lacks proofreading activity and this may be one reason why hepadnavirus populations in infected patients and animals are heterogeneous in sequence (Miller et al., 1990; Schodel et al., 1989, 1991 and references therein). For a few cloned HBV, WHV, and one GSHV genomes the infectivity or defectivity were experimentally tested (Sprengel et al., 1984; Will et al., 1985;

\footnotetext{
' Current address: Zentrum fur Molekulare Biologie, Im Neuenheimer Feld 282, 6900 Heidelberg, FRG.

${ }^{2}$ To whom correspondence and reprint requests should be addressed at Max-Planck-Institut for Biochemie, 8033 Martinsried/ München, FRG.
}

Seeger et al., 1987, 1989; Girones et al., 1989; Miller et al., 1990), and from some HBV and WHV genomes the defect is obvious because of large deletions in essential genes (Miller et al., 1990; Okamoto et al., 1987). From this limited number of experiments the number of defective mammalian hepadnavirus genomes appears to be rather high and they seem to accumulate in chronic infection.

Avian hepadnaviruses, and in particular DHBV, have served in the past as very useful tools to decipher the life cycle of hepadnaviruses and are increasingly used as model systems for antiviral drug, antibody neutralization, and virus receptor studies (Lambert et al., 1990; Schodel et al., 1989, 1991; Yuasa et al., 1991). HHBV and several genomes of DHBV were isolated, cloned, and sequenced, and a remarkable sequence variation was observed (Uchida et al., 1989; Tong et al., 1990; Mattes et al., 1990; Tong et al., 1991; Sprengel et al., 1991; and some isolates reviewed in Schodel et al., 1991). The significance of this sequence variation is not known since the infectivity of only three cloned DHBV DNA genomes was experimentally demonstrated (Sprengel et al., 1984; Schneider et al., 1991). Naturally occurring defective DHBV genomes were not identified so far.

Here we report the characterization of infectivity and defectivity of several DHBV genomes and one HHBV genome by in vivo and in vitro assays. The data obtained indicate that most cloned avian hepadnaviruses are infectious or replication competent. Two defective DHBV genomes were identified with possible defects in the pre-S/S and polymerase coding region. 


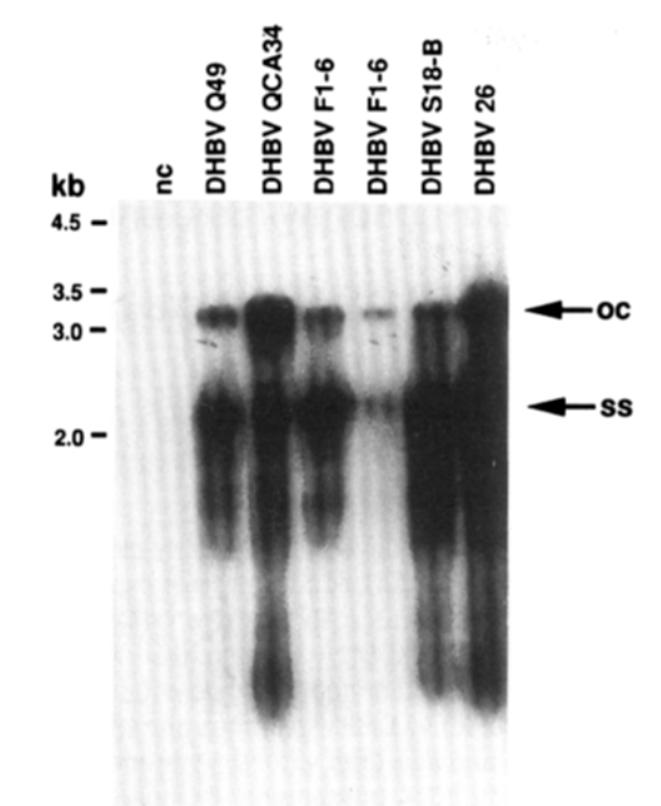

Fig. 1. DHBV replicative intermediates in livers of Pekin ducks transfected with DHBV genomes. nc, mock transfected livers; Oc, open circular form of DHBV genome; ss, single-stranded DHBV minus strand DNA.

\section{MATERIALS AND METHODS}

\section{DHBV isolates}

Cloned avian hepadnavirus genomes were derived from a goose (DHBV 1, Sprengel et al., 1991), Pekin ducks (DHBV 3, 16; Sprengel et al., 1985; Mandart et al., 1984), various other ducks (DHBV 22 and 26; Sprengel et al., 1991; DHBV S18-B, Tong et al., 1990; DHBV F1-6, Mattes et al., 1990; DHBV S5 and S31, Uchida et al., 1989; DHBV QCA34, Tong et al., 1991, and Q49, Tong and Mattes, unpublished), and from a grey heron (HHBV 4, Sprengel et al., 1988). All these genomes were cloned from virions derived from serum of naturally infected animals. Infectivity has been demonstrated so far for DHBV 3, 16, and 26 only (Sprengel et al., 1984; Schneider et al., 1991). The infectivity of the HHBV genome could not be tested in grey herons because they are under conservation protection-in Pekin ducks this genome does not induce viremia presumably due to its heron-specific host range (Sprengel et al., 1988) but a defect in the genome could not be excluded in this study.

\section{Transfection of avian liver tumor cells (LMH)}

Chicken hepatoma cells (LMH, Kawaguchi et al., 1987) were grown in petri dishes of $60 \mathrm{~mm}$ diameter and transfected by the $\mathrm{Ca}_{3}\left(\mathrm{PO}_{4}\right)_{2}$ method as described (Condreay et al., 1990). The plasmid DNAs were purified by the method of Clewell and Helinski (1969) followed by two isopycnic centrifugations in cesium chloride gradients. All plasmids used contained the corresponding DHBV or HHBV genomes as dimers in a head to tail linked conformation.

About half of the culture medium was changed 3 days after transfection; cells were harvested another 2 to 3 days later. The cells were washed twice with PBS (10 $\mathrm{mM} \mathrm{Na}_{2} \mathrm{HPO}_{4}, 2 \mathrm{mM} \mathrm{KH_{2 }} \mathrm{PO}_{4}, 170 \mathrm{mM} \mathrm{NaCl}, 3$ $\mathrm{mM} \mathrm{KCl}$ ), scraped off and lysed for $1 \mathrm{hr}$ on ice in $100 \mu \mathrm{l}$ lysis buffer consisting of $150 \mathrm{mM} \mathrm{NaCl}, 20 \mathrm{mM}$ Tris/ $\mathrm{HCl}, 10 \mathrm{mM}$ EDTA, $1 \%$ NP40, $1 \mathrm{mM}$ phenylmethylsulfonylfluoride, $\mathrm{pH} 8$. The lysate was sonified for $15 \mathrm{sec}$ before aliquots were used for immunoblotting or DNA isolation for Southern blot analysis as described (Lambert et al., 1990).

\section{Partial purification of viral particles}

Viral particles of culture medium of LMH cells $(3$ $\times 10^{6}$ cells each) transfected with various DHBV DNAs were concentrated by precipitation with $10 \%$ PEG and

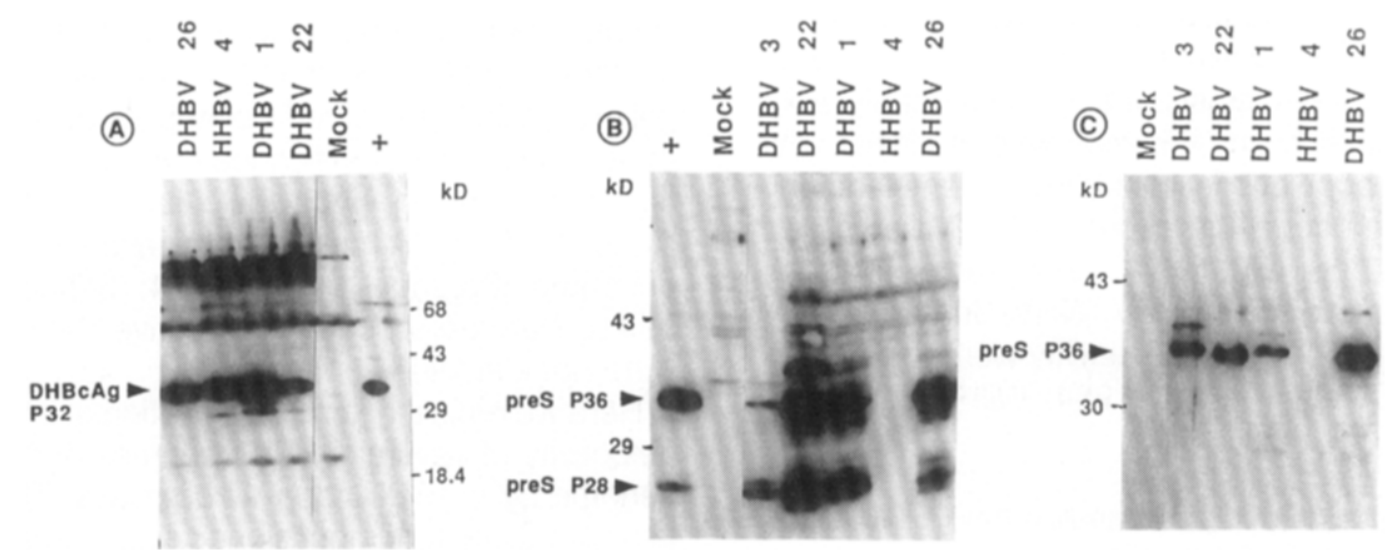

FIG. 2. Detection of nucleocapsid (A) and pre-S (B) protein expression in LMH cells transfected with cloned DHBV and HHBV 4 genomes by immunoblotting with polyclonal antibodies to recombinant DHBCAg and DHBV pre-S protein visualized by autoradiography and ${ }^{125} /$-protein $A$. In the lane designated + a cell extract from an infected duck liver was loaded. (C) Pre-S proteins in virus particles pelleted from the supernatant of transfected LMH cells was detected by immunoblotting as described above. 


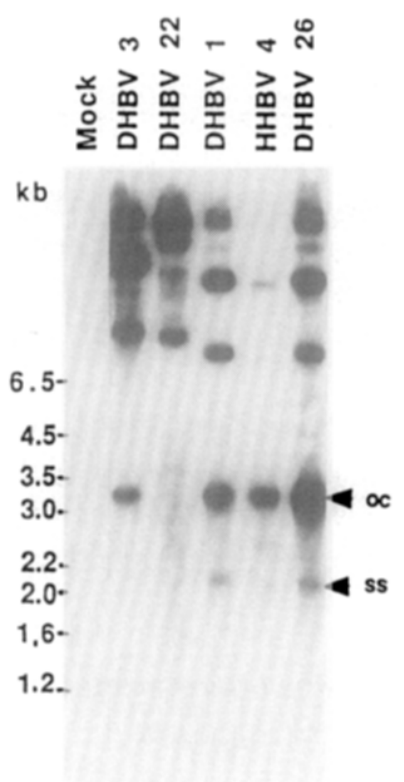

FiG. 3. Southern blot analysis of replicative intermediates extracted from transfected cells. Oc, double-stranded open circular DHBV DNA; ss, single stranded DHBV minus strand DNA.

nonencapsidated DNA was digested with DNase I as described (Summers et al., 1991). The pellets were resuspended in $\mathrm{CsCl}$ and the particles were separated by ultracentrifugation for $2 \mathrm{hr}$ at $80 \mathrm{krpm}$ in a TLV 100 rotor. The gradients were divided into three large fractions (from bottom to top densities were $1.29,1.27$, and $1.24 \mathrm{~g} / \mathrm{cm}^{3}$; core particles (density, $1.35 \mathrm{~g} / \mathrm{cm}^{3}$ ) pellet under these condition whereas virions stay on top) and were analyzed for virion DNA by Southern blotting after pelleting of the virions with SDS, Proteinase $K$ digestion, phenol and chloroform/isoamylalcohol extraction, and precipitation of the DNA by ethanol as described (Summers et al., 1991).

\section{Detection of viral proteins by immunoblotting}

Cell lysates and viral particles pelleted from culture supernatants ( $\frac{1}{5}$ of total from each) were applied on

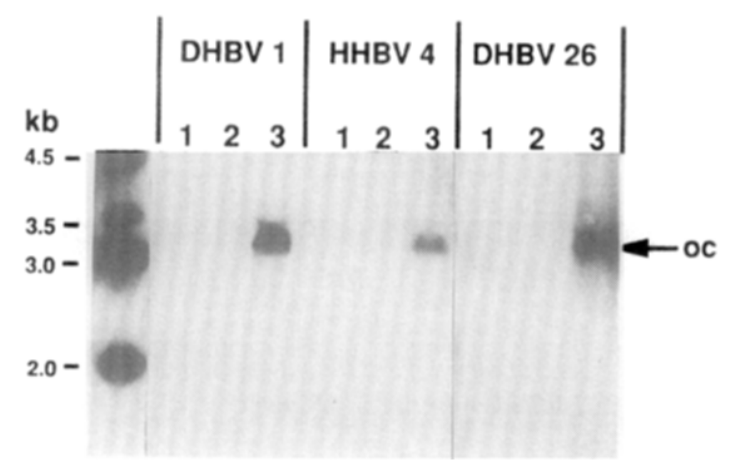

Fig. 4. Southern blot analysis of viral DNA extracted from viral particles purified by $\mathrm{CsCl}$ centrifugation ( 1 to 3 each denote a pool of bottom, middle, and top fractions of the gradient). oc, doublestranded open circular DHBV DNA.

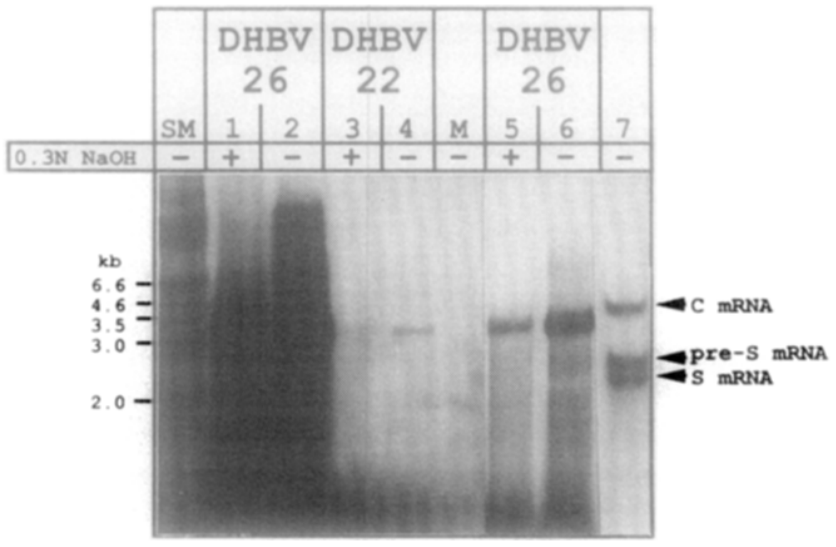

FIG. 5. Analysis of core particle-encapsidated pregenomic RNA in LMH cells transfected with DHBV 26 and DHBV 22:DNA. Lanes 1 to 4: long exposure; lanes 5 and 6 : short exposure. Total polyA+ RNA isolated from a DHBV 3 infected liver (lane 7) and DNA restriction fragments (lane SM) were run as size markers. ${ }^{+}$and - denote whether or not the RNA was pretreated with $0.3 \mathrm{~N} \mathrm{NaOH}$ before loading.

$17.5 \%$ SDS-polyacrylamide gels. Immunoblotting was performed as described (Lambert et al., 1990). Cell lysates and suspensions of pelleted viral particles were boiled in SDS-sample buffer (3\% SDS, 2\% 2-mercaptoethanol, $10 \%$ glycerol, $0.1 \%$ bromophenol blue, 5 mM EDTA, $200 \mathrm{mM}$ Tris- $\mathrm{HCl}, \mathrm{pH} 6.8$ ), cleared by centrifugation for $5 \mathrm{~min}$ in an Eppendorf centrifuge, and the supernatant was loaded on the gel. After electrophoretic transfer of the proteins from the gel to the nitrocellulose filter, unspecific binding sites were blocked overnight with PBS/5\% BSA. For detection of pre-S proteins and viral particles in cellular lysates a polyclonal rabbit anti-pre-SAg serum (anti-pre-S-Kpn; Lambert et al., 1990) and for detection of core proteins an antiDHBCAg serum (anti-C2989, Schneider et al., 1991) were diluted 1:2000 in PBS/1\% BSA and incubated with the nitrocellulose-sheets for $2 \mathrm{hr}$ at RT or overnight at $4^{\circ} \mathrm{C}$. The blots were washed $3 \times$ with PBS/ $0.1 \%$ Tween before ${ }^{125}$-Protein A (diluted 1:2000 in PBS/1\% BSA) was added for $2 \mathrm{hr}$. After washing $4 \times$ with PBS $/ 0.1 \%$ Tween the nitrocellulose filters were dried and exposed to an X-ray film.

\section{Analysis of viral DNA by Southern blotting}

Replicative intermediates of viral DNA were isolated essentially as described (Summers et al., 1990) using $0.5 \mathrm{mg} / \mathrm{ml}$ Proteinase $K$ instead of Pronase. After phenol extraction and ethanol precipitation the DNA was analyzed by agarose gel electrophoresis, transferred to nitrocellulose filters, and hybridized using a gel-purified EcoRI full-length genome fragment of DHBV 26 DNA radiolabeled with ${ }^{32} P_{-} \alpha d C T P$ to a specific activity of $10^{8} \mathrm{cpm} / \mu \mathrm{g}$. 


\section{Isolation and analysis of viral RNA}

Transfected cells were lysed in lysis buffer and $\mathrm{MgAc}_{2}$ and DNAse I was added to obtain a final concentration of $6 \mathrm{mM}$ and $100 \mu \mathrm{g} / \mathrm{ml}$, respectively. Core particles were precipitated from these lysates with $6 \%$ PEG 8000 in $350 \mathrm{mM} \mathrm{NaCl}, 10 \mathrm{mM}$ EDTA by incubation for 30 min at $4^{\circ}$ and centrifugation in an Eppendorf centrifuge for $4 \mathrm{~min}$ at $4^{\circ}$. The pellet was resuspended in $200 \mu$ of Tris $-\mathrm{HCl}, \mathrm{pH} 8$, and treated with nuclease S7 (final concentration: $100 \mu \mathrm{g} / \mathrm{ml}$ nuclease $\mathrm{S} 7,6 \mathrm{mM}$ $\mathrm{MgCl}_{2}, 1 \mathrm{mMCaCl}, 50 \mu \mathrm{g} / \mathrm{ml} \mathrm{t}-\mathrm{RNA}$ ) for $20 \mathrm{~min}$ at $37^{\circ}$. The reaction was stopped by addition of $10 \mathrm{mM}$ EGTA, and proteins were digested with Proteinase $K$ (in 0.1 $\mathrm{mM}$ Tris- $\mathrm{HCl}, \mathrm{pH} 7.5,12 \mathrm{mM}$ EDTA, $150 \mathrm{mM} \mathrm{NaCl}$, $1 \% \mathrm{SDS}$ ) for $30 \mathrm{~min}$ at $37^{\circ}$. The RNA was extracted once with phenol and twice with chloroform/isoamylalcohol $(24: 1 \mathrm{v} / \mathrm{v})$ and after addition of $10 \mu \mathrm{g}$ of t-RNA precipitated with ethanol. Extraction of total RNA and preparation of polyA+ RNA from a liver infected with DHBV 3 was pertormed and analyzed by Northern blot analysis as described (Büscher et al., 1985). To ensure that no DNA is present in the RNA isolated from cores an aliquot of the RNA was treated for $5 \mathrm{~min}$ at $100^{\circ}$ with $0.3 \mathrm{~N} \mathrm{NaOH}$, neutralized with $\mathrm{HCl}$, and precipitated with ethanol.

\section{RESULTS}

\section{Infectivity of cloned DHBV genomes in vivo}

The infectivity of 10 cloned DHBV genomes (DHBV 1, 22, QCA34, Q49, S18-B, F1-6, S5, and DHBV 3, 26 and 16 as positive controls) was tested in vivo by injecting the cloned double-stranded viral DNA into the liver of 1 to 3 day-old ducklings (five animals for each type of DNA) negative for markers of previous DHBV infection, as previously described (Sprengel et al., 1984). Three weeks after injection of the DNA, the animals were sacrificed and the blood and livers were tested for the presence of replicative intermediates and for $\mathrm{DHBcAg}$ and pre-S protein expression in the liver, as well as for viral DNA and pre-S protein in the serum by Southern and immunoblotting, respectively, as described previously (Lambert et al., 1990). Except DHBV 1 and DHBV 22, all other DHBV genomes induced in 3 to 5 animals all viral markers tested. Pre-S protein and DHBV DNA titers were similar to those in animals infected with control virus (data not shown). Representative examples showing the replicative intermediates in the liver of animals transfected with cloned
DHBV DNAs are shown in Fig. 1. Except for DHBV S5, serum from animals with these replicative intermediates in the liver was used for infection of two to five animals to further confirm the infectivity of the virus produced. One to 2 weeks after inoculation all these animals had similar high levels of pre-S and core proteins in the serum and in the liver (data not shown) as when inoculated with DHBV of proven infectivity (DHBV 3 or 16) (Schneider et al., 1991). These data indicate that five of the newly analyzed viral genomes with previous unknown infectivity (DHBV QCA34, Q49, S18-B, F1-6, and S5) induce a systemic infection whereas two of the genomes (DHBV 1 and 22) are defective.

\section{Expression of viral proteins from two defective DHBV and one HHBV genome}

To test whether the two DHBV genomes and an HHBV genome which were not infectious in Pekin ducks (HHBV was previously tested for infectivity in vivo; Sprengel et al., 1988) are defective for expression of viral nucleocapsid and pre-S protein expression, LMH cells were transfected with the cloned viral DNAs. By immunoblotting using an antibody specific for recombinant DHBcAg, strong expression of nucleocapsid protein was visualized in cell extracts prepared from LMH cells transfected with HHBV and all DHBV genomes tested (Fig. 2A). Expression was at least as efficient as that seen with cells transfected with an infectious DHBV 26 genome (Fig. 2A). An analogous experiment using antibodies to a recombinant DHBV pre-S protein revealed in the same cell extracts pre-S proteins qualitatively and quantitatively similar to an infectious DHBV genome (Fig. 2B). The $36-\mathrm{kDa}$ band corresponds to the major pre-S protein, the 28$\mathrm{KDa}$ band is a processing product of P36 (Lambert et al., 1990; Fernholz and Will, unpublished). Minor bands with lower or higher electrophoretic mobilities than pre-S protein P36, which were only seen in transfected $\mathrm{LMH}$ cells, are minor pre-S proteins initiated at internal AUGs of the pre-S open reading frame (D. Fernholz and $H$. Will, unpublished data) and some of them probably also modified and processed forms of P36. The pre-S protein of HHBV, if present in these cell extracts, could not be visualized because DHBV pre-S antibodies do not cross-react with HHBV pre-S proteins due to substantial sequence divergence from DHBV pre-S (Sprengel et al., 1988, Schneider et al., 1991). To test whether the pre-S proteins produced inside the cells are secreted and form virus particles, the medium of

FIG. 6. Comparative analysis of all published avian hepadnavirus sequences of the pre-S/S (A), nucleocapsid (B), and pol (C) proteins. Indicated are the translation initiation sites (underlined) and transcription initiation sites (arrows). Amino acid changes unique to the defective DHBV 1 (A and $\mathrm{B}$ ) and DHBV $22(\mathrm{C})$ proteins are enboxed. 
A

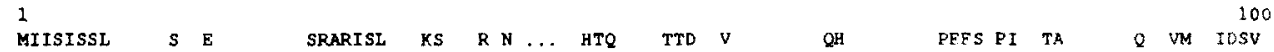

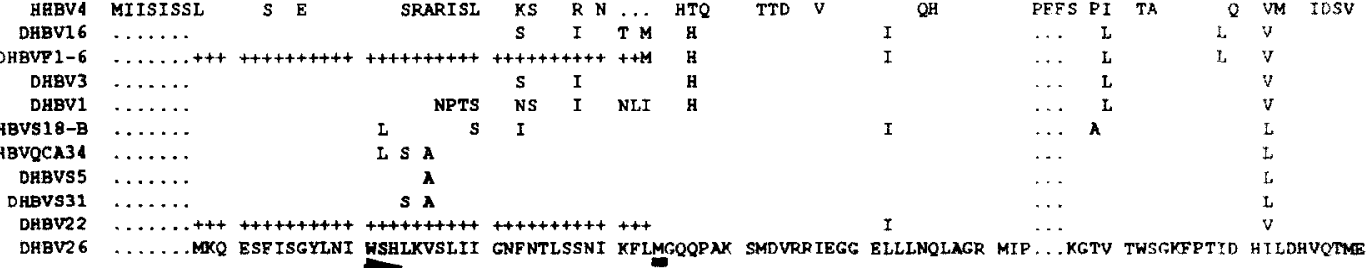

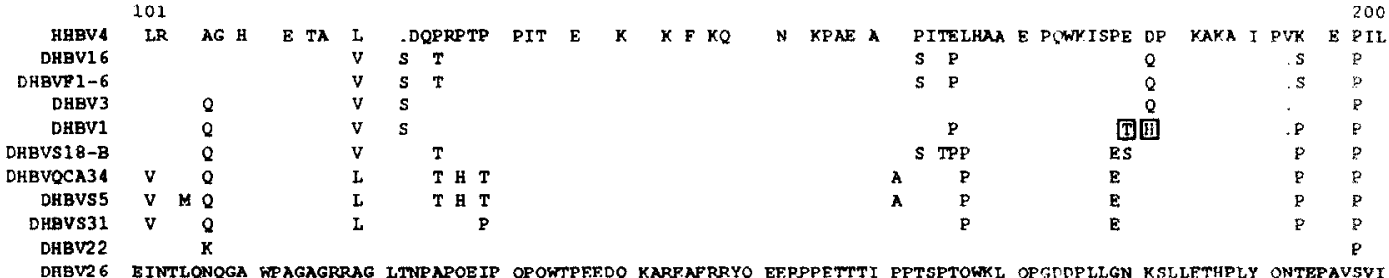
201

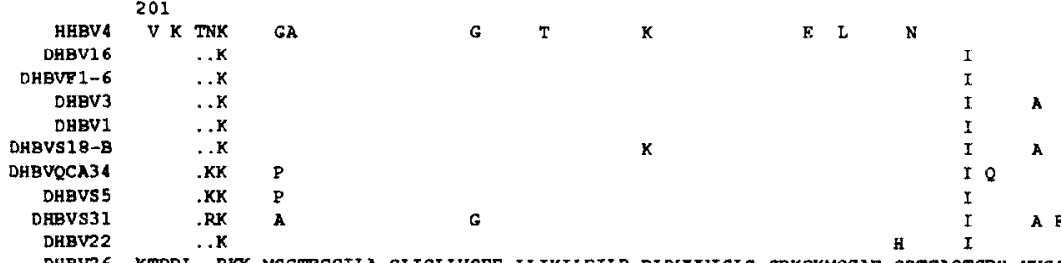

DHBV2 6 KTPPL. . RKK MSGTFGGILA GLIGLLVSFF LLIKILEILR RLDWWISLS SPKGKMQCAF QDTGAQTSPH YVGSCPWGCP GFLWTYLPYF IIFLLILLYA

\begin{tabular}{|c|c|c|c|c|c|c|c|c|c|c|c|c|c|c|c|c|c|}
\hline & 01 & & & & & & & & & & & & & & & & 379 \\
\hline HHBV4 & $\mathbf{F}$ & E K & & FE & $Q$ & $s$ & & 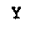 & $\mathbf{z}$ & $\mathrm{T}$ & $\mathbf{F}$ & $r$ & $\mathrm{v}$ & $\mathrm{v}$ & & & F NSG \\
\hline DHBV16 & & & & & Q A & $s$ & $\mathbf{F}$ & & & $T$ & $s$ & & & & & & \\
\hline DHBVF $1-6$ & & & & & $Q A$ & $s$ & $\mathbf{F}$ & & & $\mathbf{T}$ & $s$ & & & & & & \\
\hline DHBV 3 & & & & & $Q \AA$ & $s$ & $\mathbf{Y}$ & & & $T$ & $s$ & & & & & & \\
\hline DHBV1 & & & & & Q A & $s$ & $\mathbf{F}$ & & & $T$ & $s$ & & & & (8) & & \\
\hline DHBVS18-B & & & & & $Q A$ & $s$ & $\mathbf{F}$ & & 0 & & & & & & & & \\
\hline DHBVQCA34 & & M & I & $\mathbf{E}$ & $Q$ & sv & $\mathbf{F}$ & & $Q$ & & & & & & & $\mathrm{v}$ & $\mathrm{N}$ \\
\hline DHBVS 5 & & $M$ & I & & $\underline{Q}$ & $s$ & $\mathbf{F}$ & & 0 & I & & & & & & & $\mathbf{N}$ \\
\hline DHEVS31 & & $M$ & I & & $\mathbf{Q}$ & $s$ & $\mathbf{F}$ & & $Q$ & & & & & & & & $\mathrm{~N}$ \\
\hline
\end{tabular}

B

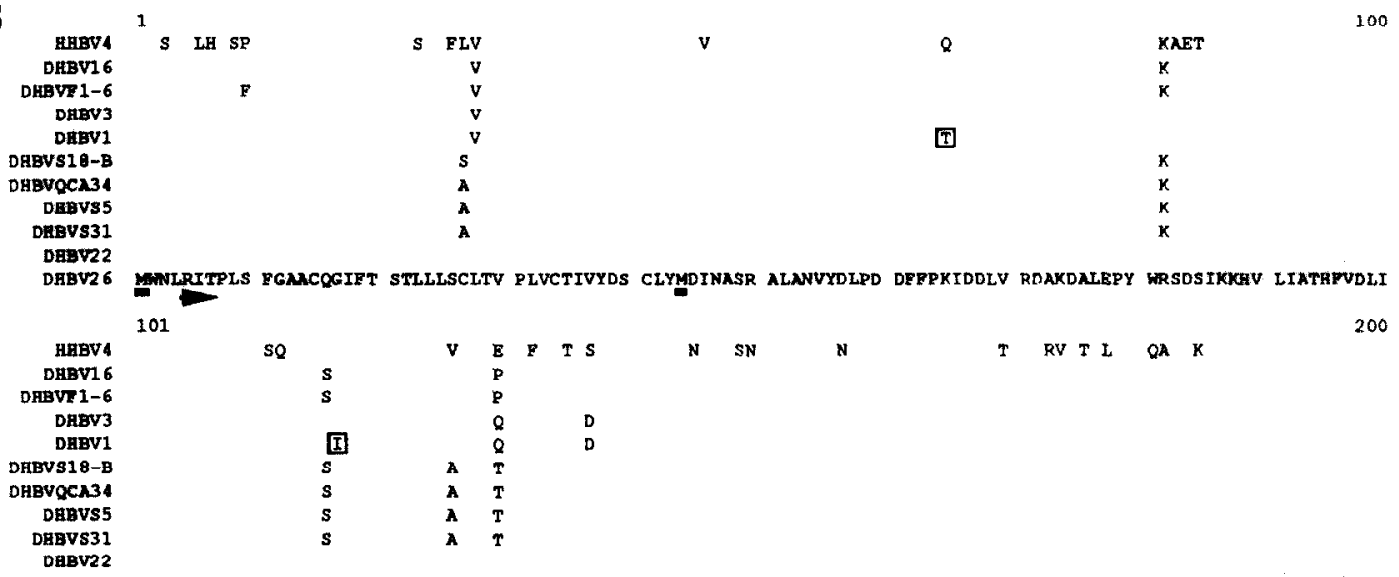

DHBV26 BDFWOTTQGM GE IAEATRAV IPPTTTPVPA GYLIQHEEAE EIPLGDLFKH QFRRIVSFOP DYPITARTHA HL.FAYAKINE ESLDRARRLL WHAYNCLTWC

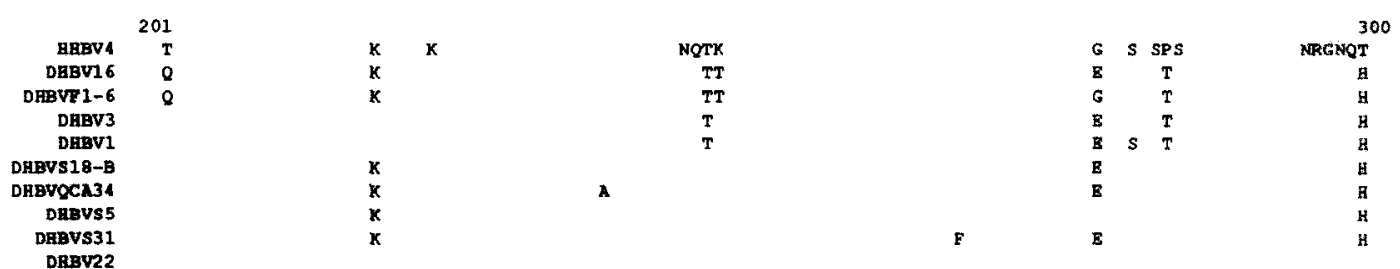

DHBV26 BANVTNYISR LRTWLSTPRR YRGRDAPTIE AITRP IQVAQ GGRXTSSGTR KPRGLEPRRR KVITTVVYGR PR SKSRDRRA PSPORAGSPI PRSSSSHRRS

301

DABV16

10

DBBv

DHBVS18-B

DABUSS

DAgVs3

PSPRK 
C

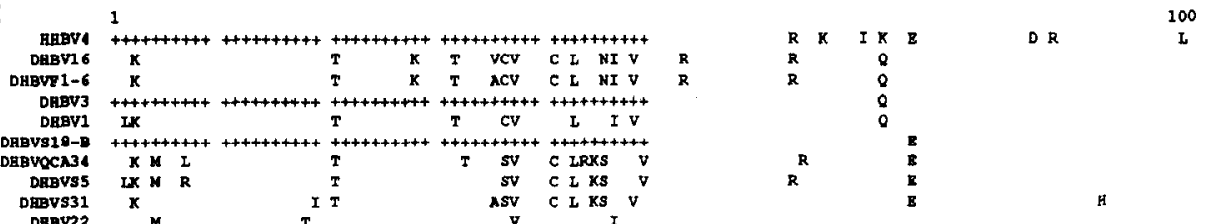

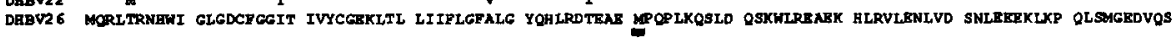

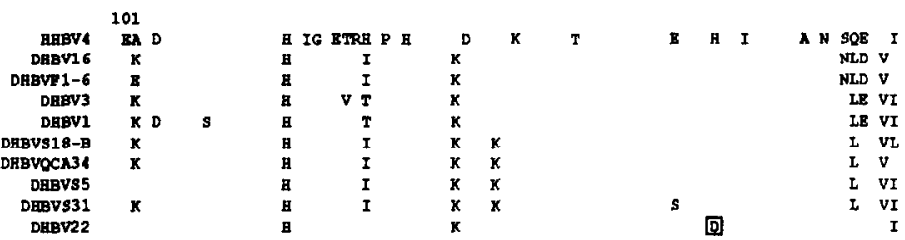

B
K

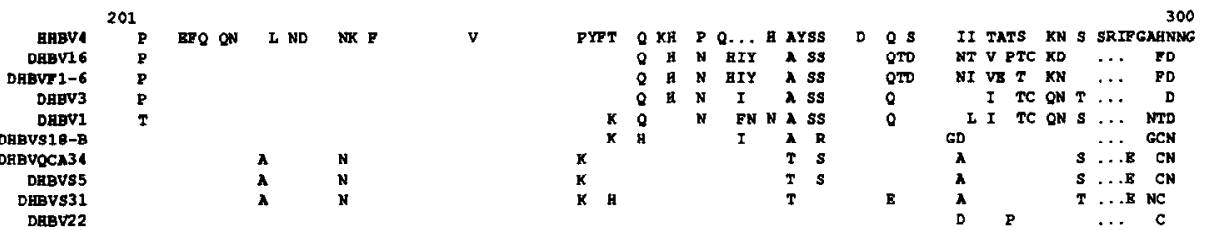

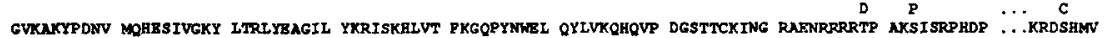

BHEV4 RK YHSTRD GSHRLS RTS DPTSRGA G GOSTPIC.PG TAAHP THA $R$ OKGQ GVLQAI BP SETRRNGTTS AERVARCR $S$ SVEDE TRRPY

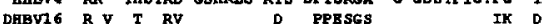

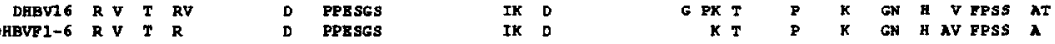

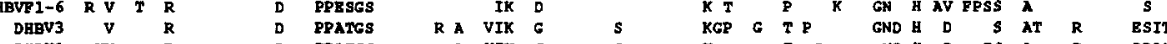

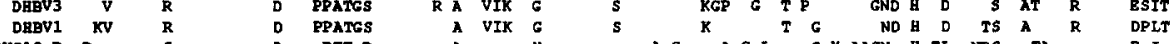

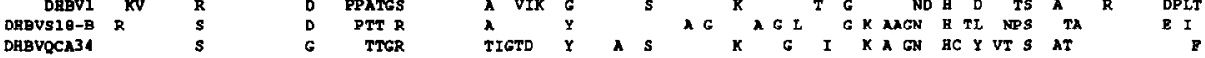

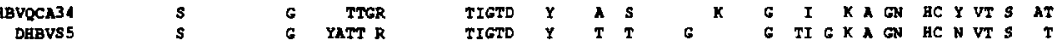

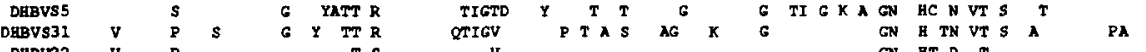

DHBV26 GQISNMRSHI RPCNNGGGNK HSSKPRGLAC WGGKRSRINO SCSSRDSSAP VDSRRRSZSS RSFSSLSRRE TTRDHFNSSH ISNAVETATR GRSTPGKQVS 401

HHBVA TQSKE $Y$ RQ GTRETDPOGP KAHOOS

DABQI6 P $S$ I . V T GASD $\mathrm{N}$. . PL B

DAVT1-6 P S I V T GASD $\mathrm{T}$. . PI

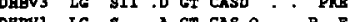

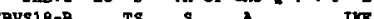

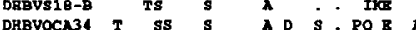

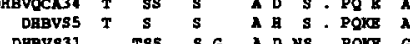

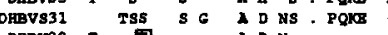

DHBV26 ARDSPALPEY RASRVCIKD. .SSTEKBNYW YLRGNTSWPN RITGKLFLVD KNSRNTSEAR LWVDESQFSK GKNAMREPRY WSPNLSTLRR ILPVGMPRIS

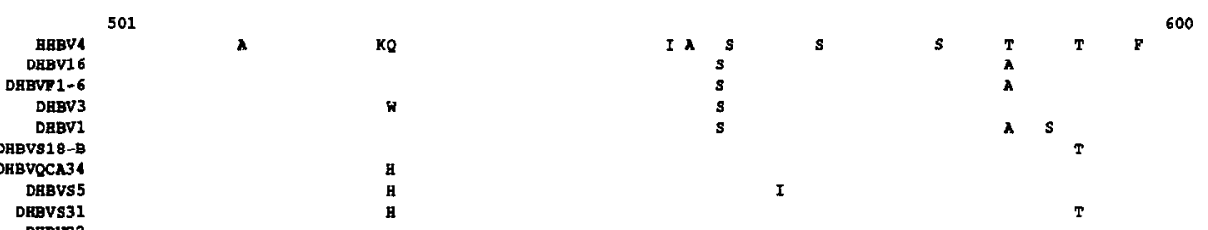

DHBV26 LDLSOAFYHL PLNPASSSRL AVSOGQRUYY PRKAPMGVGL SPFLLLLFTT ALGSEIARRg NWTTPTYMDD FLICHPNARH INSISHAVCS FLOELGIRIN

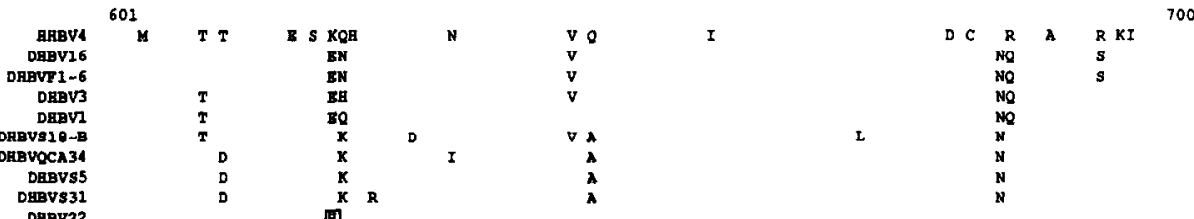

DHBV26 POKTTPSPVN BIRFLGYQID QRPAKIEESR MKELRTVIKK IKIGBWYDWN CIQRPVGALN PVLPYTKGNI EMLKPMYMAI THKVNF SPSS AYRTILYKL

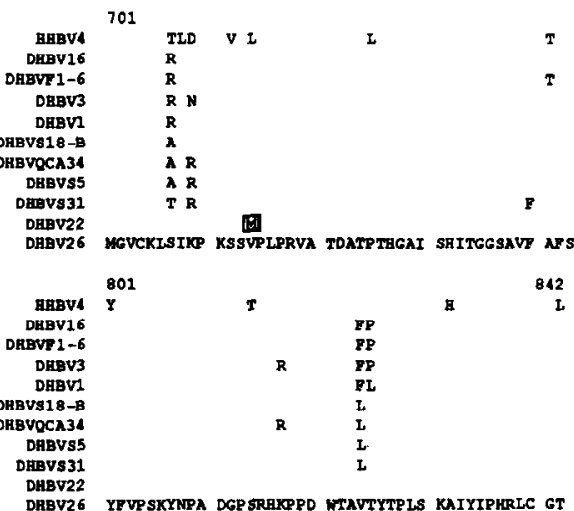

Fig. 6-Continued 
by other viral proteins produced from coinfecting DHBVs. It can, however, not be excluded with certainty that the defect arose during cloning of the DHBV genomes.

Indications as to the type of defect that renders genomes DHBV 1 and 22 noninfectious were obtained by studying synthesis of viral DNA, expression of viral proteins, and secretion of viral particles. The data obtained in vitro and in vivo suggest that genome DHBV 1 is fully functional except in the early step of the infection process. Possible candidate mutations which are responsible for DHBV 1 defectivity could be located in the envelope (pre-S/S) proteins which are believed to bind to cell specific virus receptors and mediate virus entry into the cell (reviewed in Alberti et al., 1990). To further support this speculation a comparative sequence analysis of pre-S/S protein sequences, as deduced from all cloned viral DNAs, was performed (Fig. 6). Three amino acid changes unique to the predicted DHBV 1 pre-S/S proteins were observed (enboxed in Fig. 6A). It is therefore conceivable that DHBV 1 pre-S/ $S$ proteins have an altered structure which does not allow attachment to the cells or interfere with one of the other early steps of virus cell-penetration or uncoating. A gross structural change in the DHBV 1 pre$\mathrm{S} / \mathrm{S}$ proteins induced by the observed mutations is unlikely because particle formation and secretion is unaltered. A definite answer will require studies of the interaction of the DHBV 1 pre-S/S protein with the DHBV receptor protein. Two amino acid changes unique to DHBV 1 are also present in the nucleocapsid protein; one is at a position where the HHBV core protein has also an amino acid altered, and the other is a conservative change from leucine to isoleucine (enboxed in Fig. 6B). Perhaps these mutations alter the interaction of pre-S with core protein which is involved in regulation of the copy number of intracellular cccDHBV DNA and of virion secretion (Summers et al., 1990, 1991).

The most likely defect of the DHBV 22 genome which expressed all viral proteins tested in vitro and led to secretion of viral particles is a defect of the polymerase protein(s). The comparative sequence analysis of all known DHBV pol-proteins revealed five mutations unique to DHBV 22, four of them in highly conserved regions (enboxed in Fig. $6 \mathrm{C}$ ). Three of the mutations are located at the carboxyterminal end of the pol-protein which encodes the RNase $\mathrm{H}$ domain (Schodel et al., 1988; Kudyakov and Makhov, 1989; Radziwill et al., 1990). Similar mutants were shown to be in part replication competent and to produce DHBV minus strand DNA (Radziwill et al., 1990). Southern blot analysis with DNA from DHBV 22-transfected cells revealed only a weak smear in the region of replicative intermediates but not a clear band of minus strand DHBV DNA. The smear could represent degraded plasmid DNA and/or a small amount of heterogeneous replicative intermediates. Because of these technical difficulties we can therefore currently not decide whether DHBV 22 is a RNase H-defective mutant. One of the unique DHBV 22 mutations is located in the highly conserved aminoterminal end of the pol-protein which is believed to represent at least part of the genome-linked protein (Bartenschlager and Schaller, 1988; Khudyakov and Makhov, 1989). The second possibility is, therefore, that DHBV 22 is defective because of a nonfunctional genome-linked protein. As the polymerase protein has an essential role in encapsidation of the RNA pregenome (Bartenschlager et al., 1990) and is a RNA binding protein (Kochel et al., 1991) this mutation could also prevent efficient RNA pregenome encapsidation. All these possibilities are not mutually exclusive and the combination of DHBV 22 specific mutations could also play a role. Mutational and functional analysis will provide us with answers to these questions.

In a previous report we have shown that the HHBV 4 genome is not infectious in Pekin ducks and have speculated that this is due to a heron-specific host range (Sprengel et al., 1988; Sprengel and Will, 1988). Our current study has demonstrated the replication competence of the cloned HHBV 4 genome and efficient expression of nucleocapsid protein of the predicted size. Although pre-S/S proteins could not be visualized because a corresponding antibody is not available, the observation that viral particles were shed into the medium as efficiently as from infectious DHBV genomes suggests that both pre-S and $S$ proteins are expressed. form viral particles and are secreted. Whether or not the HHBV DNA is also infectious in herons remains unknown.

\section{ACKNOWLEDGMENTS}

This work was supported by grants from the Deutsche Forschungsgemeinschaft (Forschergruppe Virus-Zellwechselwirkung, Fa 138/3-3). We are very grateful to Drs. P. L. Marion, F. Mattes, S. Tong, and $H$. E. Blum for providing us with cloned DHBV genomes. We thank K. Thomassen and $G$. Sowa for expert technical assistance and Dr. D. Schendel for critically reading of the manuscript.

\section{REFERENCES}

Alberti, A., Gerlich, W. H., Heermann, K-H., and Pontisso, P. (1990). Nature and display of hepatitis $B$ virus envelope proteins and the humoral immune response. Springer Semin. Immunopathol. 12, 5-23.

BARTENSCHLAGER, R., and SCHALLER, $H$. (1988). The amino-terminal domain of the hepadnaviral P-gene encodes the terminal protein (genome-linked protein) believed to prime reverse transcription. EMBO J. 7, 4185-4192.

BARTENSCHLAGER, R., JUNKER-NIEPMANN, M., and SCHALLER, H. (1990). The $P$ gene product of hepatitis $B$ virus is required as a structural component for genomic RNA encapsidation. J. Virol. 64, 53245332.

BÜSCHER, M., ReISER, W., WILL, H., and SChaLLER, H. (1985). Tran- 
the transfected cells was subjected to ultracentrifugation to pellet viral particles. The pellets were analyzed for pre-S proteins by immunoblotting. Pre-S proteins were identified in the pellets of all supernatants (Fig. $2 \mathrm{C})$. These data demonstrate that both defective DHBV virus genomes did not only express pre-S proteins but they were also secreted as viral particles with similar efficiencies as observed with infectious DHBV genomes.

\section{Replicative intermediates and virion DNA produced from $\mathrm{LMH}$ cells}

For both defective DHBV 1 and DHBV 22 genomes and one HHBV genome, the replication competence and the ability to produce and secrete virions were analyzed by searching for intracellular replicative intermediates of viral DHBV DNA and virion-encapsidated DHBV DNA in the medium of transfected cells. The DNA of partially enriched core particles from lysed $\mathrm{LMH}$ cells transfected with plasmids containing head to tail linked dimers of these genomes, and DNA of virus particles secreted from these cells and purified by $\mathrm{CsCl}$ centrifugation were extracted and subjected to Southern blot analysis using a ${ }^{32} \mathrm{P}$-labeled DHBV DNA probe. In the enriched core particles, major bands of open circular and minor bands of DHBV minus strand DNA (in addition to various forms of higher molecular weight input plasmid DHBV DNA) that are representative for replicative intermediates were observed with all tested DHBV genomes (except DHBV 22) and with the HHBV genome (Fig. 3). With DNA extracted from CsClpurified virions from the medium of $\mathrm{LMH}$ cells transfected with DHBV 1, DHBV 26, and HHBV 4 a single band of approximately $3.3 \mathrm{~kb}$ corresponding to virion DNA was detected (Fig. 4). In contrast, no signal was detected in medium of cells transfected with DHBV 22 (not shown) consistent with the absence of replicative intermediates in enriched core particles. These data also indicate that the defective DHBV 1 and the HHBV genomes are not only replication competent but can form and secrete virions similar to infectious DHBV genomes.

\section{Pregenomic RNA produced from DHBV 22 is inefficiently encapsidated}

Expression of similar amounts of pre-S and core proteins from the DHBV 22 genomes and absence of replicative intermediates and virions in experiments with LMH cells suggested a defect in DHBV 22 either in polymerase protein function, RNA pregenome encapsidation, or both. To test whether the DHBV 22 RNA pregenome is encapsidated, core particles from LMH cells transfected with the DHBV 22 genomic DNA or with an infectious DHBV genome as a positive control were partially purified, the RNA extracted and probed by Northern blotting for encapsidated pregenomic RNA. A strong band of about $3.3 \mathrm{~kb}$ corresponding to the DHBV RNA pregenome was seen in core particles derived from the infectious DHBV 26 genome (Fig. 5, lanes 5 and 6) whereas using the same exposure time ( $2 \mathrm{hr}$, room temperature, no intensifier screen) no signal was obtained with particles derived from the DHBV 22 genome (data not shown). After longer exposure (14 hr with intensifier screen), however, a very minor signal corresponding to the RNA pregenome was also seen with cores from DHBV 22 (Fig. 5, lanes 3 and 4). The signal intensity is, however, drastically weaker than that obtained with DHBV 26 (Fig. 5, lanes 1 to 4). These data suggest a major defect of DHBV 22 in encapsidation of pregenomic RNA.

\section{DISCUSSION}

In this study the infectivity of eight out of 10 DHBV genomes tested was demonstrated. One of two DHBV genomes (DHBV 1) and one HHBV (HHBV 4) genome which are not infectious in Pekin ducks were characterized in vitro as replication competent and were shown to produce and secrete virions in vitro whereas one DHBV genome (DHBV 22) appeared replication incompetent and produced only virus particles containing little RNA pregenome. Taken together, previously published data (Sprengel et al., 1984; Schneider et al., 1991) and the results of this study indicate that most cloned avian hepadnavirus genomes are infectious. The replication competence of HHBV and its ability to produce and secrete virions in vitro and defects in cloned DHBV genomes have so far not been reported.

The percentage of defective cloned DHBV genomes from the panel of genomes tested here is lower than that of WHV and HBV which occasionally outnumber genomes without overt defects and appear to accumulate during chronic infection (Miller et al., 1990 and references therein). Possible explanations could be that virtually all defective mammalian hepadnaviruses reported so far are from long-term chronic carriers whereas all DHBV genomes identified in our study were obtained from young or only a few years old animals. In addition, defective chromosomally integrated viral WHV and HBV DNA frequently found in chronic carriers (reviewed in Matsubara and Tokino, 1990) which can give rise to defective virion DNA by complementation is only seldomly observed in chronic DHBV carrier ducks (Yokosuka et al., 1985; Sprengel and Will, 1988). For DHBV, efficient synthesis of virions with defective viral DNA by complementation had been recently experimentally demonstrated in vitro (Horwich et al., 1990). It is likely that the defective genomes identified in our study are due to the infidelity of the reverse transcription process and were complemented 
scripts and the putative RNA pregenome of duck hepatitis B virus: Implications for reverse transcription. Cell 40, 717-724.

CLEWELL, D. B., and HELINSKI, D. R. (1969). Supercoiled circular DNAprotein complex in E. coli. Purification and induced conversion to an open circle DNA form. Proc. Natl. Acad. Sci. USA 62, 1159 1166.

Condreay, L. D., Aldrich, C. E., Coates, L., Mason, W. S., and Wu, T-T. (1990). Efficient duck hepatitis $B$ virus production by an avian liver tumor cell line. J. Virol. 64, 3249-3258.

Girones, R., Cote, P. J., Hornbuckle, W. E., Tennant, B. C., Gerin, J. L., PURCELL, R. H., and MILLER, R. H. (1989). Complete nucleotide sequence of a molecular clone of woodchuck hepatitis $B$ virus that is infectious in the natural host. Proc. Natl. Acad. Sci. USA 86 , 1846-1849.

HorWich, A. L., Furtak, K., Pugh, J., and Summers, J. (1990). Synthesis of hepadnavirus particles that contain replication-defective duck hepatitis B virus genomes in cultured $\mathrm{HuH}-7$ cells. J. Virol. $64,642-650$

Kawaguch, T., Nomura, K., Hirayama, Y., and Kitagawa, T. (1987). Establishment and characterization of a chicken hepatocellular carcinoma cell line, LMH. Cancer Res. 47, 4460-4464.

KHUDYAKOV, Y. E., and MAKHOV, A. M. (1989). Prediction of terminal protein and ribonuclease $\mathrm{H}$ domains in the $\mathrm{P}$ gene product of hepadnaviruses. FEBS Lett. 243, 115-118.

KÖCHEL, H. G., KANN, M., and THOMSSEN, R. (1991). Identification of a binding site in the hepatitis $B$ virus RNA pregenome for the viral pol gene product. Virology 182, 94-101.

Lambert, V., Fernholz, D., Sprengel, R., Fourel, I., Deléage, G., Wildner, G., Peyret, C., Trepo, C., Cova, L., and WILL, H. (1990). Virus-neutralizing monoclonal antibody to a conserved epitope on the duck hepatitis B virus pre-S protein. J. Virol. 64, 1290-1297.

MANDART, E., KAY, A., and GALIBERT, F. (1984). Nucleotide sequence of a cloned duck hepatitis $B$ virus genome: comparison with woodchuck and human hepatitis B virus sequences. J. Virol. 49, 782 792.

MARION, P. (1988). Use of animal models to study hepatitis B virus. Prog. Med. Virology 35, 43-75.

MATSUBARA, K., and Tokino, T. (1990). Integration of hepatitis B virus DNA and its implications for hepatocarcinogenesis. Mol. Biol. Med. 7, 243-260.

Mattes, F., Tong, S., Teubner, K., and Blum, H. E. (1990). Complete nucleotide sequence of a German duck hepatitis $B$ virus. Nucleic Acid Res. 18, 6140.

Miller, R. H., Girones, R., Cote, P. J., Hornguckle, W. E., ChestNut, T., BaldWin, B. H., Korba, B. E., Tennent, B. C., Gerin, J. L., and PURCELL, R. H. (1990). Evidence against a requisite role for defective virus in the establishment of persistent hepadnavirus infections. Proc. Natl. Acad. Sci. USA 87, 9329-9332.

OKAMOTO, H., TSUDA, F., and MAYUMi, M. (1987). Defective mutants of hepatitis $B$ virus in the circulation of symptom-free carriers. Jpn. J. Exp. Med. 57, 217-221.

RADZIWILL, G. TUCKER, W., and SCHALLER, H. (1990). Mutational analysis of the hepatitis $B$ virus $P$ gene product: domain structure and RNase $\mathrm{H}$ activity. J. Virol. 64, 613-620.

SCHNEIDER, R., FERNHOLZ, D., WILDNER, G., and WILL, H. (1991). Mechanism, kinetics and role of duck hepatitis $B$ virus e-antigen expression in vivo. Virology 182, 503-512.

SCHÖdel, F., Weimer, T., WiLL, H., and Sprengel, R. (1988). Amino acid sequence similarity between retroviral and $E$. coli RNase $H$ and hepadnaviral gene products. AIDS Res. Human Retrovir. 4, 9-11.

Schödel, F., Sprengel, R., Weimer, T., Fernholz, D., Schneider, R., and WILL, H. (1989). Animal hepatitis B viruses. Adv. Vira/ Oncol. 8, 73-102.

SCHÖdEL, F., WeIMER, T., FERNHOLZ, D., SCHNeider, R., SPREnGel, R., WILDNER, G., and WILL, H. (1991). The biology of avian hepatitis $B$ viruses. In "Molecular Biology of Hepatitis B Virus." (A. McLachlan, Ed.), CRC Uniscience, in press.

Seeger, C., Marion, P. L., Ganem, D., and Varmus, H. E. (1987). In vitro recombinants of ground squirrel and woodehuck hepatitis viral DNAs produce infectious virus in squirrels. /. Virol. 61, 3241 3247.

SeEger, C., Balowin, B., and Tennant, B. C. (1989). Expression of infectious woodchuck hepatitis virus in murine and avian fibroblasts. J. Virol. 63, 4665-4669.

Sprengel, R., KuHn, C., Manso, C., and WILL, H. (1984). Cloned duck hepatitis $B$ virus DNA is infectious in Pekin ducks. I. Viro/. 52, 932-937.

SPRENGEL, R., KUHN, C., WILL, H., and SChALLER, H. (1985). Comparative sequence analysis of duck and human hepatitis $B$ virus genomes. J. Med. Virol. 15, 323-333.

SPRENGEL, R., KALETA, E. F., and WILL, H. (1988). Isolation and characterization of a hepatitis B virus endemic in herons. J. Virol. 62 , 3832-3839.

SPRENGEL, R., and WILL, H. (1988). Duck hepatitis B virus. p. 363 386. In "Virus Disease in Laboratory and Captive Animals" (G Darai, Ed.), Nijhoff, Boston.

Sprengel, R., Schneider, R., Marion, P. L., Fernholz, D., Wiloner, G., and WILL, H. (1991). Comparative sequence analysis of defective and infectious avian hepadnavirus genomes. Nucleic Acids Res., in press.

SUMmERS, J., SMITH, P. M., and HORWICH, A. L. (1990). Hepadnavirus envelope proteins regulate covalently closed circular DNA amplification. J. Virol. 64, 2819-2824.

SUMMERS, J., SMITH, P. M., HUANG, M., and YU, M. (1991). Morphogenetic and regulatory effects of mutations in the envelope proteins of an avian hepadnavirus. J. Virol. 65, 1310-1317.

TONG, S., MATtes, F., Teudner, K., and BLum, H. E. (1990), Complete nucleotide sequence of a Chinese duck hepatitis $\mathrm{B}$ virus. Nucleic Acid Res. 18, 6139.

Tong, S., Mattes, F., Blum, H. E., Fernholz, D., Schneider, R., and WILL, H. (1991). EMBL X60213.

UCHiDA, M., EsUmi, M., and SHIKATA, T. (1989). Molecular cloning and sequence analysis of duck hepatitis $B$ virus genomes of a new variant isolated from Shanghai ducks. Virology 173, 600-606.

Will, H., Cattaneo, R., Daral, G., Deinhardt, F., Schellekens, H., and SCHALLER, H. (1985). Infectious hepatitis $B$ virus from cloned DNA of known nucleotide sequence. Proc. Natl. Acad. Sci. USA 82, 891-895.

WiLl, H., Reiser, W., Weimer, T., Pfaff, E., Büscher, M., Sprengel, R., Cattaneo, R., and SCHALleR, H. (1987). Replication strategy of human hepatitis B virus. J. Virol. 61, 904-911.

YOKOSUKA, O., OMATA, M., ZHOU, Y-Z., IMAZEKI, F., and OKUDA, K. (1985). Duck hepatitis $B$ virus DNA in liver and serum of Chinese ducks: Integration of viral DNA in a hepatocellular carcinoma. Proc. Natl. Acad. Sci. USA 82, 5180-5184.

Yuasa, S., Cheung, R. C., Pham, Q. Robinson, W. S., and Marion, P. L. (1991). Peptide mapping of neutralizing and nonneutralizing epitopes of duck hepatitis B virus pre-S polypeptide. Virology 181 , 14-21. 